\title{
In-line Measurement of Tempered Cocoa Butter and Chocolate by Means of Near-Infrared Spectroscopy
}

\author{
Stefan Bolliger, Yuantong Zeng, and Erich J. Windhab* \\ Laboratory of Food Engineering, Department of Food Science, Swiss Federal Institute of Technology (ETH), \\ 8092 Zurich, Switzerland
}

\begin{abstract}
In the present work cocoa butter and chocolate were precrystallized by means of a newly developed shear crystallizer. The shear crystallizer was integrated into a circular loop. The handling of precrystallized cocoa butter showed a high dependency on the timing of applied analysis. Differential scanning calorimetry, calorimetry, rheometry, and in-line nearinfrared (NIR) were all directly influenced by the fat crystal structure. Nevertheless, for cocoa butter it was shown that mechanical energy input (rpm) had a significant influence on viscosity, melting enthalpy, and slope at the second point of inflection of a temper curve. Experiments with cocoa butter at constant exit temperature showed a linear increase of viscosity between 0.1 and $0.8 \mathrm{~Pa} \cdot \mathrm{s}$ in the range of 300 to $1300 \mathrm{rpm}$. Melting enthalpy increased in the same rpm interval from 0.02 to $2.5 \mathrm{~J} / \mathrm{g}$. Solidification time (from 4.5 to $0.5 \mathrm{~min}$ ) and slope (from 0.82 to 0.15 , second point of inflection of temper curve) consequently decreased (both with exponential approximation). For cocoa butter, slope and solidification time correlated linearly whereas solidification time and viscosity followed a power law fit. This proved that defined relationships exist between rheological data and data from temper curve measurements. Viscosity was linearly dependent on crystal content. By means of NIR spectroscopy good correlation models for cocoa butter viscosity, enthalpy (crystal content), and slope values were found. For precrystallized chocolate, analytical values such as viscosity and slope values were detected off-line and used for calibration of NIR spectroscopy.
\end{abstract}

Paper no. J8712 in JAOCS 76, 659-667 (June 1999).

KEY WORDS: Chocolate, cocoa butter, crystallization, differential scanning calorimetry, in-line measurement, near-infrared spectroscopy, process control, temper curve, viscosity.

Tempering (precrystallization) is one of the main process steps influencing product quality in chocolate manufacturing. The aim of the precrystallization step is to produce crystal nuclei in the preferred $\beta_{\mathrm{V}}$ - and /or $\beta_{\mathrm{VI}^{-}}$-modifications. It is furthermore important to maintain low viscosities of the precrystallized mass in order to obtain good flow properties in the subsequent process steps (molding, covering). In conventional precrystallization manufacturing, different temperature

*To whom correspondence should be addressed at Laboratory of Food Engineering, Swiss Federal Institute of Technology, Schmelzbergstrasse 9, 8092 Zurich, Switzerland. E-mail: windhab@ilw.agrl.ethz.ch stages (in general, three) are passed through before the chocolate mass exits the process line with a temperature of 29-31 ${ }^{\circ} \mathrm{C}$.

Systematic studies on the influence of shear forces on the precrystallization of chocolate masses were carried out by Windhab et al. (1) and Ziegleder (2). In the work of Windhab et al. (1) a shear stress controlled experiment was carried out in the rheometric gap using a cone and plate configuration. Typical viscosity-time functions resulted when a mechanical "activation-level" $(\tau \approx 0.5 \mathrm{~Pa})$ at cooling temperatures of $<25^{\circ} \mathrm{C}$ was passed. With increasing shear stress, a reduction of the steady-state viscosity (shear thinning) and a significant shortening of crystallization time were detected. By means of calorimetric measurements (differential scanning calorimetry, DSC) it was proven that, by increasing shear stress level, an increasing amount of crystals in the stable $\beta_{\mathrm{V}}$-modification was generated (1). These results can be applied to a continuous process setup (continuous shear crystallizer) (3). Increased rotor speed in a shear crystallizer led to a significant acceleration of crystallization for dark chocolate. On the other hand, high numbers of nuclei are of beneficial effect against fat bloom in chocolate products. According to Ziegleder (4) a large number of crystal nuclei during crystallization can be achieved by the influence of shear.

Various publications propose methods to characterize the level of precrystallization. According to Kleinert (5), a specific temperature-time quotient derived from the cooling curve can be used as a characteristic measure of the crystallization velocity. This quotient can be approximated by the slope in the second inflection point of the cooling curve. Motz (6) also used cooling curves to determine the degree of precrystallization. He proposed however, using the gradient (sign omitted) of a tangent laid to the first part (between 29 and $26^{\circ} \mathrm{C}$ ) of the curve. Gradually released latent heat of crystallization results in a change in the gradient value. Well-pretempered chocolate showed values between 1.05 and 1.15, whereas untempered chocolate had values between 2.6 and 2.8, and overtempered showed values between 0.9 and 0.55 . Thus, going from an untempered state to a tempered state slows the cooling of the chocolate sample and therefore causes the gradient to decrease.

In Ziegleder et al. (7) DSC and nuclear magnetic resonance (NMR) were compared, and DSC was found to be more accurate in defining the state of precrystallized chocolate. It 
was found that the crystal content was directly related to the temperature of the precrystallized mass, and the same results were found for one- and two-stage precrystallization. A method for direct measurement of thermal properties for milk fat, based on calibrated NMR, was presented by Breitschuh and Windhab (8). In Windhab et al. (1), an in-line calorimeter was introduced. With it, the measurement of a cooling curve (temper curve) on the basis of an improved tempering principle is possible. To date, however, there has been no systematic work on the quantitative correlation between crystallization kinetics, crystal modification distribution in the product, and specific volumetric energy input in defined flow fields.

The goal of this work was to describe the rotor speed-dependent crystallization characteristics of a newly developed shear crystallizer using in-line near-infrared (NIR) spec- troscopy. For comparison purposes off-line rheology, calorimetry, and temper curve analytics were also used. NIR spectroscopy was carried out by introducing the light fiber directly into the outlet pipe of the shear crystallizer. Results from the different off-line analytics were used to calibrate the NIR spectrometer in order to use it for direct in-line process control of the related tempered chocolate characteristics.

\section{MATERIALS AND METHODS}

Process setup. Cocoa butter and chocolate were precrystallized using a shear crystallizer (Fig. 1) built in the mechanical workshop at the Institute for Food Process Engineering/ ETH Zurich. The preheated liquid mass $\left(50^{\circ} \mathrm{C}\right)$ was pumped through the shear crystallization module, the measurement

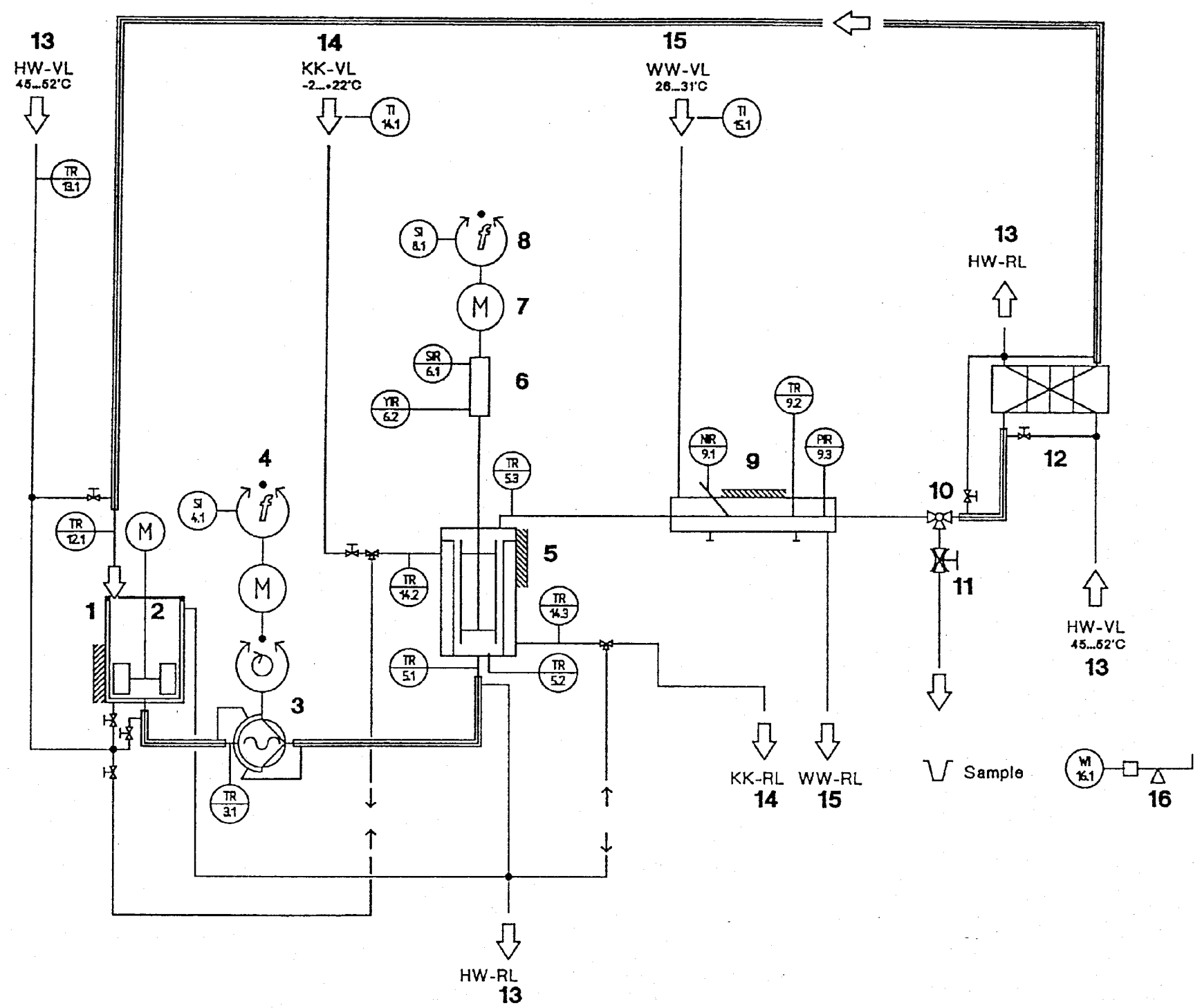

FIG. 1. Process scheme of the shear crystallization unit with storage vessel, pump, crystallizer and heat exchanger. In-line near-infrared measurements are carried out at the exit of the crystallizer at position 9. Key: 1, Storage vessel; $\mathbf{2}$, stirrer; $\mathbf{3}$, pump; 4, frequency modulator; 5, shear crystallizer; 6, revolution/torque control; $\mathbf{7}$, motor; $\mathbf{8}$, frequency modulator; $\mathbf{9}$, adapter for near infrared measurement; 10, three-way valve; 11, sample collection valve; 12, heat exchanger; 13, hot water; 14, cooling fluid; 15, warm water; 16, mass flow measurements. $\mathrm{N}$, near-infrared; $\mathrm{P}$, pressure; $\mathrm{S}$, revolution; $\mathrm{T}$, temperature; $\mathrm{W}$, mass; $\mathrm{Y}$, torque. 
adapter, a heat exchanger (P5 RB, Alfa Laval, Lund, Sweden), and finally back to a stirring vessel. The shear crystallization module consists of a modified scraped surface heat exchanger with reduced shear gap width (adjustable between 1 and 6 $\mathrm{mm})$. Attached at opposite positions on the rotor are two scrapers to remove the newly formed crystals from the wall. The gap width (between cylinder and rotor shaft) in the system was set to $6 \mathrm{~mm}$. The fluid was pumped through the axial direction. The velocity field was helical, resulting from superposition of the axial and the rotational shear profiles. The inner cylinder can be varied in speed, thus acting shear forces can be adjusted. The flow resulting by the use of this system led to extensive homogeneous heat and material transport. By means of the helical flow within the shear crystallizer gap, the dissipated energy, the crystallization enthalpy, and the latent heat can be transferred efficiently to the cooling jacket. Rotor speed was varied by use of a frequency modulator within the range of 100-1300 rpm. The tempering of the cooling jacket was done by use of a cooling water bath (Julabo FPW55, Julabo $\mathrm{GmbH}$, Seelbach, Germany). The tempering of the storage vessel and the product pipes was done by means of a warmwater circulator at $50^{\circ} \mathrm{C}$. At the exit of the crystallization unit, an adapter was mounted to insert the NIR light fibers into the product flow. The main process parameter investigated was rotor speed of the shear crystallization unit, which varied within the interval of 300-1300 rpm. The setpoint for a new $\mathrm{rpm}$ was randomly selected. From $300-550 \mathrm{rpm} n=2$, from 600-1000 $\operatorname{rpm} n=3$, and $n=1$ between 1100 and $1300 \mathrm{rpm}$.

Constant cocoa butter outlet temperature. The mass flow was set to $20 \mathrm{~kg} / \mathrm{h}$. After setting the rotor speed, the cooling temperature was set such that the exit temperature of the cocoa butter reached a constant value $\left(25.0^{\circ} \mathrm{C}\right)$. Fifteen minutes after reaching the constant exit temperature (equilibrium), analytical measurements (NIR, calorimetry, DSC, rheometry) were carried out as described below. The inlet temperature of the cocoa butter into the shear crystallization module was always $48.0^{\circ} \mathrm{C}$.

After the measurements for a specific process set point, the cooling jacket was fed with hot fluid to melt down all the crystals. Then a new rotor speed setting was carried out. When the exit temperature of the product reached $45^{\circ} \mathrm{C}$, the jacket was cooled down again to reach an exit temperature of $25.0^{\circ} \mathrm{C}$ and a new experiment (new rpm and cooling temperature setting) was performed. Experiments with cocoa butter were carried out within the interval of 300 to $1300 \mathrm{rpm}$.

Constant chocolate outlet temperature. The mass flow was set to $27 \mathrm{~kg} / \mathrm{h}$. After setting the rotor speed, the cooling temperature was set such that the exit temperature of the chocolate reached a constant value $\left(28.7^{\circ} \mathrm{C}\right)$. The inlet temperature of the chocolate entering the shear crystallization module was $48.0^{\circ} \mathrm{C}$. Cooling curves for precrystallized chocolate were determined and slope values calculated. At the exit of the shear crystallizer, in-line NIR spectras were acquired. The results from calorimetry, DSC, and rheometry were then used to calibrate the NIR spectroscopy. This calibration resulted in mathematical models, from here on referred as NIR calibration models.
Application of NIR calibration models. The calibration models were applied for in-line NIR measurements. Two different process setups were carried out: (i) Constant outlet temperature: On-line measurements of crystal content, viscosity, and slope were performed over 300-1300 rpm, with $25 \mathrm{rpm}$ as the smallest step size. The setting was randomly assigned. (ii) Constant cooling temperature: At a cooling temperature of $23.1^{\circ} \mathrm{C}$ and a mass flow rate of $20 \mathrm{~kg} / \mathrm{h}$, the rotor speed of the shear crystallizer was varied. As described previously, analytical measurements were carried out $15 \mathrm{~min}$ after reaching temperature equilibration. For mass flow rates of $17.5 \mathrm{~kg} / \mathrm{h}$ (constant cooling temperature: $23.4^{\circ} \mathrm{C}$ ) and 25 $\mathrm{kg} / \mathrm{h}$ (constant cooling temperature: $22.6^{\circ} \mathrm{C}$ ) on-line measured viscosity values were taken at different rotor speed settings. Special care was taken to ensure that off-line analysis was carried out according to a pre-set timetable. The sequence was in the following order: NIR, calorimetry, DSC, and rheometry. Thus, NIR was carried out at a very early stage after a crystal had nucleated. Nucleation would therefore represent the zero point on such a time axis, and the time between nucleation and actual measurement would be relevant for the size of an individual crystal. In the calorimetry procedure where a cooling curve is measured, the entire mass was brought to nearly $100 \%$ crystallization. The time between sampling and introduction into the calorimetry vessel was kept constant. When compared to NIR, DSC and rheometry were carried out later on the above time axis, therefore allowing more time for crystal growth. When comparing DSC and rheometry, points on the time axis did differ slightly.

$D S C$. Samples were taken directly from the process and introduced (approximately $20 \mathrm{mg}$ ) into an aluminum measuring cup $(80 \mu \mathrm{L})$ and then measured in the DSC device (DSC Gold, Polymer Laboratories, Rheometric Scientific GmbH, Bensheim, Germany). For all measurements an empty aluminum pan was used as a reference. The DSC insert temperature was set to $24^{\circ} \mathrm{C}$. The starting temperature was $25^{\circ} \mathrm{C}$, the heating rate $4^{\circ} \mathrm{C} / \mathrm{min}$, and the end temperature $40^{\circ} \mathrm{C}$. Calibration of the DSC device was made utilizing pure gallium (melting point: $29.8^{\circ} \mathrm{C}$, specific melting enthalpy: $80.1 \mathrm{~J} / \mathrm{g}$ ). Before the measurement, the weight of the crucibles was determined. Measurements were taken without covering the crucibles to save time and to prevent additional crystallization of the sample. Between sampling and the start of measurement approximately $60 \mathrm{~s}$ passed. A horizontally set base line type was chosen to calculate the specific melting enthalpy. To quantify the crystal content for the use of the NIR calibration models, a melting enthalpy of $137 \mathrm{~J} / \mathrm{g}$ (cocoa butter, $\beta_{\mathrm{V}}$-modification) was used according to Schuster-Salas and Ziegleder (9). The calculation was, however, based on the assumption that $100 \%$ of the crystals would be in $\beta_{\mathrm{v}}$-modification.

Viscosity measurement. The viscosity of the precrystallized products (cocoa butter, chocolate) was measured off-line in a Bohlin viscometer (Bohlin Visco V88, Bohlin Instruments Inc., Cranbury, NJ), which works on a Searle principle. The measuring system was a coaxial cylinder with a cylindrical gap width of $0.7 \mathrm{~mm}$. The shear rate was set to $28.4 \mathrm{~s}^{-1}$. The viscosity, 
measured after $21.7 \mathrm{~s}$, was defined as the viscosity of the precrystallized product and used for comparison. That is, the first viscosity measurement was obtained at $21.7 \mathrm{~s}$. Afterward, viscosity values were measured and recorded every $20 \mathrm{~s}$.

To characterize the solidification kinetics, a characteristic solidification time $\left(t^{*}\right)$ was defined as the time when a viscosity value of $\eta\left(\dot{\gamma}=28.4 \mathrm{~s}^{-1}\right)=1 \mathrm{~Pa} \cdot \mathrm{s}$ was reached in the ascending viscosity-time graph (Fig. 2). Hence, this is an arbitrary value for comparison. This increase of viscosity curve was caused by the formation of cocoa crystals during cooling to a set bath temperature of $25^{\circ} \mathrm{C}\left(29^{\circ} \mathrm{C}\right.$ for chocolate). Although this represents the crystallizer outlet temperature, cocoa butter exiting the crystallizer did not reach its energetic minimum, thus crystallization continued during the rheometric measurement.

Calorimetry. To determine the temper curves of the precrystallized products an Exotherm 7000 Tempermeter (Systech Analytics, Neuchâtel, Switzerland) was used. The temper curve is a temperature vs. time curve resulting from uniform cooling $\left(8^{\circ} \mathrm{C}\right.$ water bath) of the precrystallized sample while precisely measuring the temperature in the sample. The sample volume utilized was $20 \mathrm{~mL}$. The slope of the tangent in the second point of inflection of the cooling curve was calculated, from here on referred as slope. This inflection is caused by the release of latent heat of crystallization during a defined static cooling process. The slope at the second point of inflection thus represents an indicator of rate of crystallization. As a general rule, undertempered chocolate samples show the highest slopes (above +0.6 ), and overtempered the lowest values (below -0.6). Well-tempered samples are found between the extremes. The measurement of the cooling temperature in the center of a copper cylinder filled with chocolate and immersed in a $15^{\circ} \mathrm{C}$ water bath was also carried out. From this cooling curve, the slope of the first point of inflection was derived and from here on is referred to as s-value.

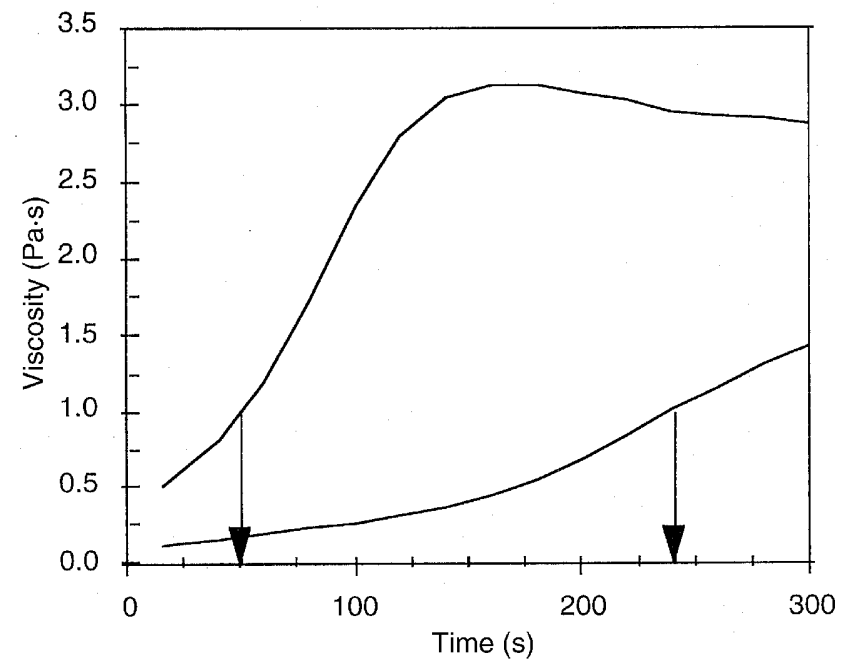

FIG. 2. Determination of solidification time, $t^{*}$, based on viscosity-time graph as shown for two different measurements (Solidification time $t^{*}=$ time when a viscosity limit of $1 \mathrm{~Pa} \cdot \mathrm{s}$ was reached in the ascending viscosity-time graph).
This value is an indicator where the heat of crystallization is first detected. Hence, unprecrystallized chocolate would show a fast decrease and precrystallized chocolate a more modest decrease due to the release of crystallization enthalpy.

NIR spectroscopy. Measurements were carried out by means of a universal spectrometer (NIRVIS with the software version BCAP 4.40, CH Bühler AG, Uzwil, Switzerland). The NIRVIS system is capable of using the entire spectral band width of 1000 to $2500 \mathrm{~nm}$ for measurement as well as for calibration. The light fiber probe was inserted in the outlet tube of the shear crystallizer by means of a special adapter. Measurements for cocoa butter were taken with a transflection probe using a measuring gap width of $5 \mathrm{~mm}$ between the end of the probe and a standardized reflection surface. Thus, the transflection probe is a combination of a transmission and a reflection measurement and is used for transparent media. Measurements for chocolate were done by means of a reflection probe (light is reflected from sample only). Therefore, all measurements of spectral data were carried out in-line. NIR spectra do not allow visual interpretations. Therefore, NIR spectra are analyzed by means of mathematical methods such as the Fourier analysis. By means of statistical methods, such as principal component analysis (PCA), a correlation between different spectral data and the data from off-line analysis (e.g., viscosity) can be established. Mathematical models in this work were approximated using the partial least squares method (PLS). Quantitative NIR correlation models in this work were built with analytical data (acquired on off-line basis) from viscosity, crystal content, slope (from temper curve), and solidification time measurements. The calibration is based on PCA. By means of PCA each spectrum is represented by a single point in a 500-dimensional space, where each dimension represents a single wavelength. Hence, the entire spectrum is used for calibration.

Once the NIR spectrometer had been calibrated (this is the first step) the spectrometer could be used (applied) to calculate product charactersitics by means of the appropriate calibration model (second stage) based on the measurement of a single spectrum.

\section{RESULTS AND DISCUSSION}

Constant cocoa butter outlet temperature. With increasing rpm the difference between exit and inlet cooling temperature grows approximately linearly, as is seen in Figure 3. Beginning at $800 \mathrm{rpm}$, the cooling jacket temperature (data not shown) has to be lowered in order to maintain outlet temperature $T$ to compensate for rising mechanical energy dissipation in the shear gap. Measured data for viscosity, solidification time, melting enthalpy, and slope as a function of rpm are shown in Figure 4A-D. These figures are presented as mean values \pm standard deviation of one experiment with multiple measurements. Viscosity and melting enthalpy of precrystallized cocoa butter show approximately linear growth when rpm are increased. Values for solidification time and slope show a nonlinear decline. The increase of melting enthalpy as 


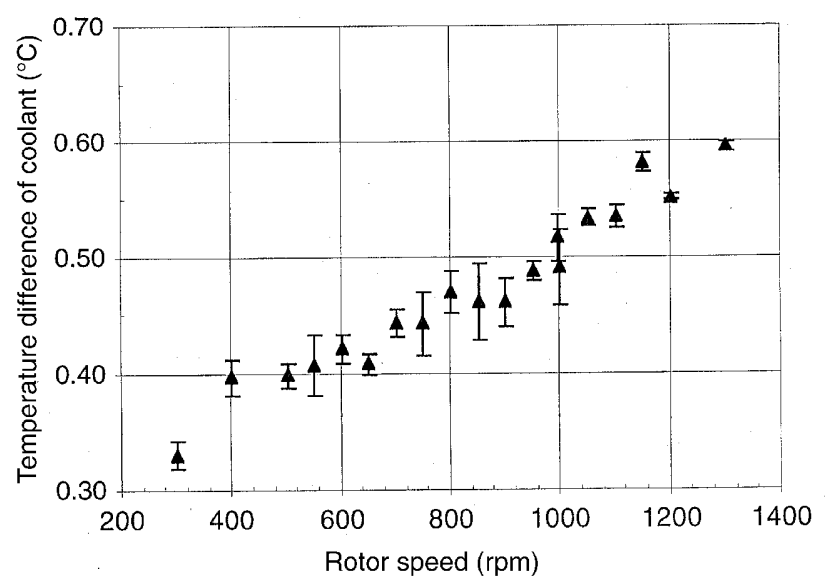

FIG. 3. Influence of rpm of the shear crystallizer on the difference between exit and inlet temperatures of the cooling fluid (shear crystallizer; cocoa butter outlet temperature $=25^{\circ} \mathrm{C}$; mass flow rate $=20 \mathrm{~kg} / \mathrm{h}$; cooling fluid, water). Error bars represent standard deviations for multiple measurements.

a function of rpm is probably not entirely related to the fact that with increasing rpm a change from energetically less stable modifications (predominantly $\beta_{\mathrm{IV}}$-modification at a melt-
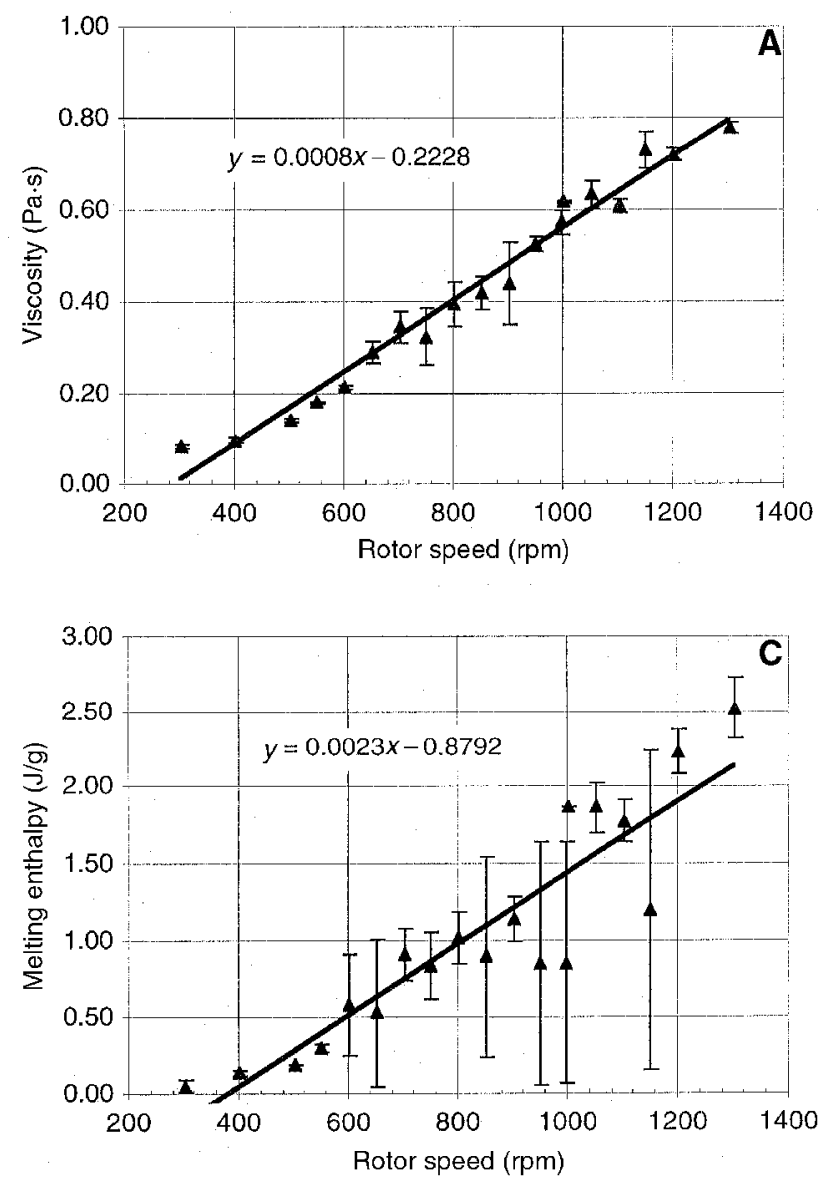

ing enthalpy of $117 \mathrm{~J} / \mathrm{g}$ ) to more stable modifications (predominantly $\beta_{\mathrm{V}}$-modification at a melting enthalpy of $137 \mathrm{~J} / \mathrm{g}$ ) occurred. Otherwise it would be difficult to understand the nonlinear decline for solidification time, for example, which is a strong indication that the crystal content in fact has increased with rpm. It could therefore be concluded that, independent of the actual temperature (which was a constant-temperature setting), the "state of crystallization" can be different: At the highest rpm settings, a cocoa butter that crystallizes at a much faster rate exits the surface scraped heat exchanger (compare Fig. 4B), thus causing higher DSC readings at a set temperature/time measurement protocol. Cocoa butter exiting at lower rpm, however, crystallized much slower and thus reached lower melting enthalpy values (Fig. 4C). The enthalpy measurements are also characterized by high standard deviations relative to the overall change of mean values in the rpm interval of 300-1300 rpm. Ziegleder (7) suggested that high standard deviations in his data were related to technology (process related, such as duration of tempering) and/or analysis. For the latter explanation he included the tempering of analysis equipment, sampling, instru-
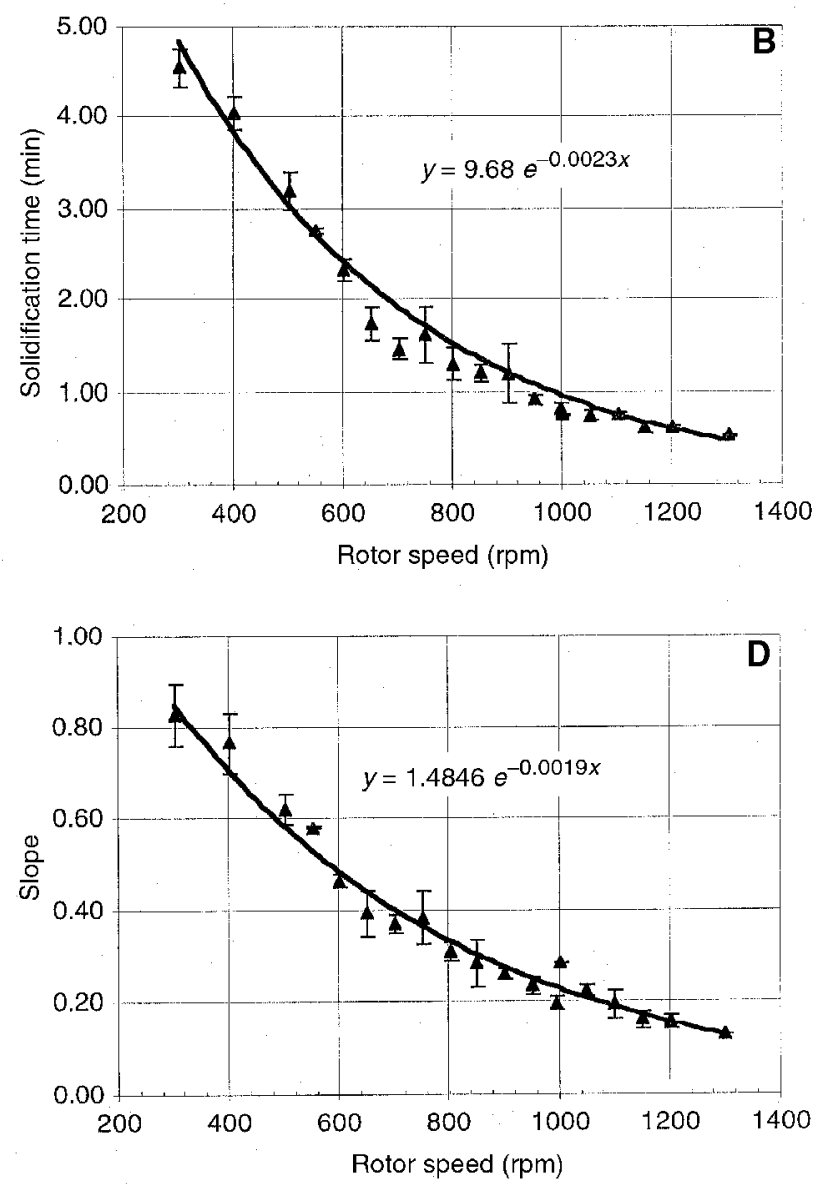

FIG. 4. Variations (determined off-line) as a function of rpm in a shear crystallizer with a constant cocoa butter outlet temperature $\left(25^{\circ} \mathrm{C}\right)$ and mass flow $=20 \mathrm{~kg} / \mathrm{h}$. (A) Viscosity at $\dot{\gamma}=28.4 \mathrm{~s}^{-1}, t=21.7 \mathrm{~s}$; (B) solidification time $t^{*}$ (viscometer Bohlin V88; $t^{*}=$ time reading at a viscosity of 1 Pa.s; c.f. Fig. 2); (C) melting enthalpy (heating rate $4^{\circ} \mathrm{C} / \mathrm{min}$, from 25 to $40^{\circ} \mathrm{C}$ ); (D) slope values (Tempermeter Exotherm 7000 ; bath temperature $8^{\circ} \mathrm{C}$; slope $=$ tangent in second point of inflection of cooling curve). All data represent means \pm standard deviation of one experiment with multiple measurements. 
mental errors, and calibration as sources of errors. Additionally precise timing for the thermodynamically highly unstable crystal suspension becomes a key factor for reducing errors.

The functional connection between the initial viscosity reading after the 21.7-s viscosity and crystal content is demonstrated in Figure 5. The calculation of crystal content is based on a specific melting enthalpy of $137 \mathrm{~J} / \mathrm{g}$ and the assumption that $\beta_{\mathrm{V}}$-modification is dominant. For a measured melting enthalpy of $1 \mathrm{~J} / \mathrm{g}$, for example, a crystal content of $0.73 \%$ crystals with $\beta_{\mathrm{v}}$-modification can be calculated. From suspension rheology the calculation for relative viscosity $\eta_{\text {rel }}$ is, according to Einstein $(10,11)$

$$
\eta_{\text {rel }}=\eta_{\text {suspension }} / \eta_{\text {fluid }}=1+2.5 c_{v} \quad\left(c_{v}<\approx 3 \%\right)
$$

where $c_{v}=$ suspension volume expressed in percentage of total volume. With Equation 1 the suspension viscosity $\eta_{\text {suspension }}$ is derived based on crystal content measurements by means of DSC. The Einstein constant of 2.5 (also called intrinsic viscosity) is valid for monodisperse rigid spheres. Intrinsic viscosity increases when deviations from a sphere occur, aggregates appear, or van der Waals forces between particles occur. According to Weipert et al. (12), an intrinsic viscosity of 4.3 can be found for cocoa solids in cocoa butter. If a factor of 4.3 is used in Equation 1 instead of 2.5, then a calculated suspension viscosity (lower straight line, $y=$ $\left.0.0708 \cdot 4.5 \cdot c_{v}+0.0708=0.3186 \cdot c_{v}+0.0708\right)$ as depicted in Figure 5 results. To have a perfect fit between measured and calculated viscosity, the intrinsic viscosity in Equation 1 would have to reach a value of $7.99\left[\left(\eta_{\text {rel }}=(0.5657 / 0.0708) \cdot c_{v}\right.\right.$ +1 , the equation for measured suspension viscosity in Figure 5 was divided by the viscosity of the fluid]. Thus, there is a deviation between calculated and measured values.

Possible reasons for this deviation are related to crystal parameters. Cocoa butter crystals are known to have dendritic shapes that deviate from spheres. Thus, even stronger crystalcrystal interactions (than expressed with an intrinsive viscosity of 4.3) or the influence of crystal shape/size (increase of hydrodynamic diameter) is responsible for the higher measured relative viscosity (upper curve, Fig. 5) compared to the calculated

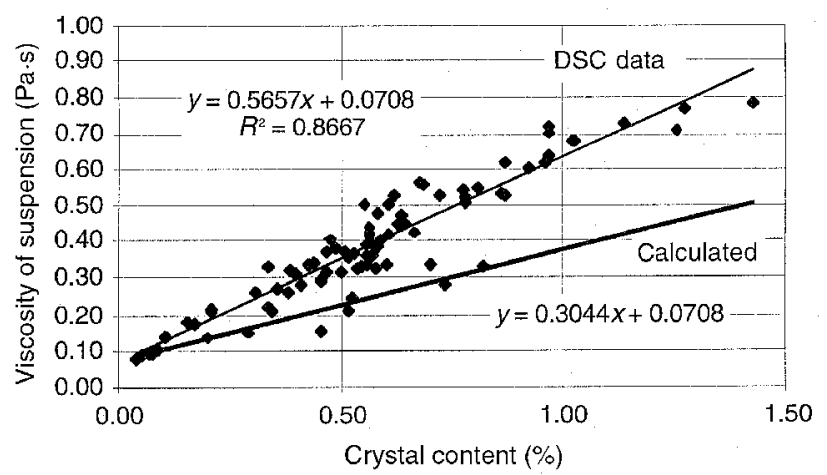

FIG. 5. Viscosity as a function of crystal content for precrystallized cocoa butter (shear crystallizer, outlet temperature $=25^{\circ} \mathrm{C}$, mass flow $=$ $20 \mathrm{~kg} / \mathrm{h}$, upper curve is measured and lower calculated based on Equation 1 , intrinsic viscosity of 4.3 , and melting enthalpy of $137 \mathrm{~J} / \mathrm{g}$ ). one. Higher melting enthalpies correlated well with higher rpm (Fig. 4C). Regarding the overall trend in Figure 4C, one expects that with higher rpm the mean fat crystal diameter decreases. However, the two wall-scraping devices in the shear crystallizer may promote secondary nucleation of cocoa butter. Secondary nucleation is thereby defined as the creation of new crystal units from already existing crystals by resulting separation. This causes an increase in total numbers of fat crystals, thereby promoting faster crystallization under a set time/temperature program in the DSC. Such a decreasing effect on mean crystal size with increasing rpm of a rotating shaft, similar to the one used in this work, was shown for ice crystals by Bolliger (13). Furthermore, with increasing crystal content and melting enthalpy with higher rpm (Fig. 4C), respectively, an increasing number of smaller crystals will be formed and therefore crystal-crystal interactions will be stronger. Stronger crystal interactions lead to an increased viscosity.

On the other hand it is also possible that not all the crystals were in the $\beta_{\mathrm{V}}$-modification, as assumed earlier. A calculation of crystal content based on $100 \%$ in the $\beta_{\mathrm{IV}}$ form and an enthalpy value for the $\beta_{\mathrm{IV}}$-modification of $117 \mathrm{~J} / \mathrm{g}$ gave a straight-line approximation $(y=0.4831 x+0.0708)$, similar to the measured suspension viscosity in Figure 5. However, an intrinsic viscosity of only $6.82\left(=0.4831 / 0.0708 \cdot c_{v}+1\right)$ would be necessary to lead to a close fit of calculated and measured viscosity. Therefore, we conclude that the main reasons for deviations in Figure 5 are related shape/size influence rather than in the type of modification.

Crystal concentrations $c_{v}$ in Equation 1 likely deviated from actual crystal concentrations at the time of viscosity measurement because no thermal equilibrium (energy minimum) has yet been reached by the precrystallized cocoa butter suspension. The difference in measurement points on the time axis (zero point $=$ time of crystal nucleation) most likely caused a difference in the average crystal size/crystal volume attained at the time of measurement. One can assume that at the time of measurement average cocoa butter crystal size for rheometric measurement was larger and crystal content higher than for DSC measurement. This would lead to a steeper viscosity-concentration graph compared to a calculation based on DSC.

The exact reason for the deviations seen in Figure 5 is almost impossible to deduce. Further studies should address the following critical control points: (i) absolutely equal timing between DSC and rheometry measurement; (ii) determination of crystal modification range by means of synchrotron radiation X-ray diffraction study; (iii) determination of intrinsic viscosity; (iv) crystal size analysis.

An approximately linear correlation was found between the solidification time and the slope values (Fig. 6A). In accordance with the general rule for slope values the higher slope values were found for higher solidification times, thus pointing toward less tempered cocoa butter. On the other hand lower slope values indicated fast crystallization behavior (Fig. 6A), thus a higher temper degree and higher viscosities (Fig. 6B). The dependency found suggests a linear correlation between slope and solidification time, thus crystallization kinetics. 

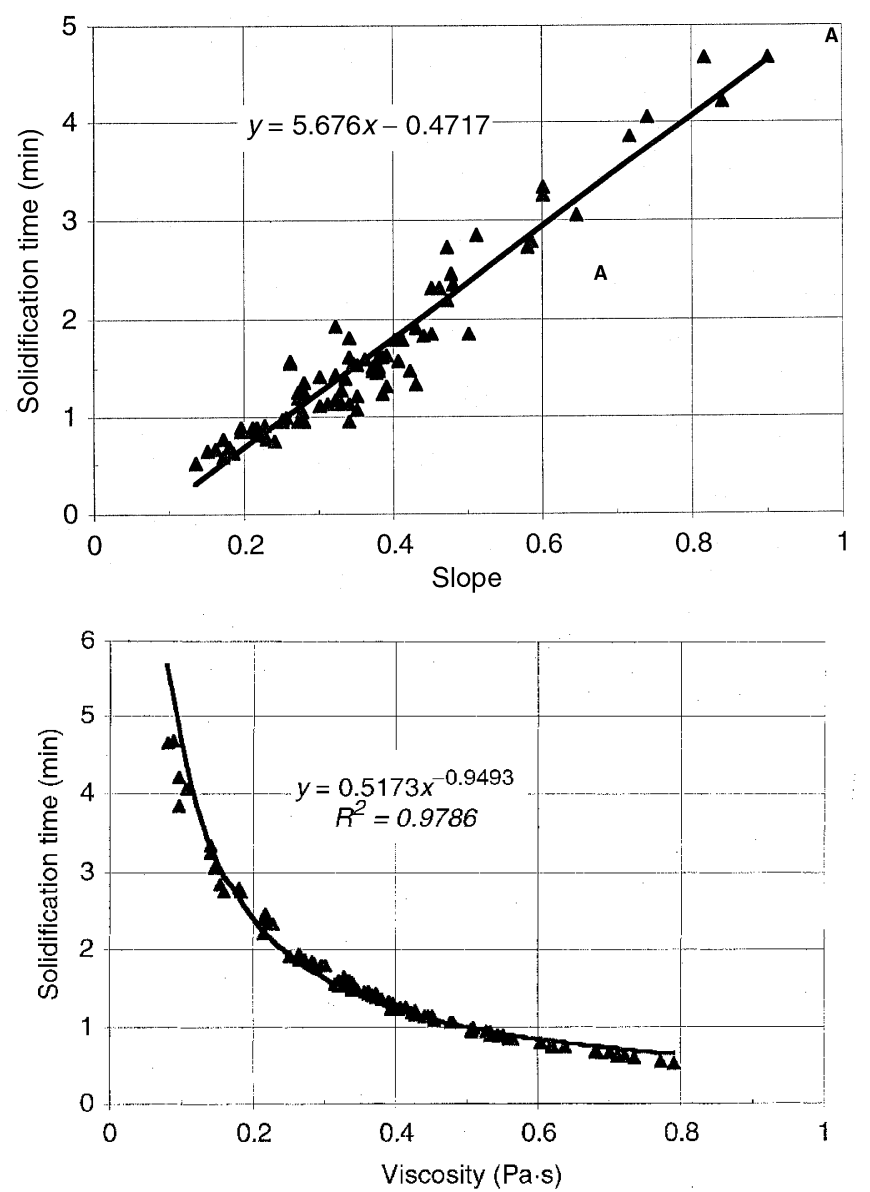

FIG. 6. Solidification time as a function of (A) slope and (B) viscosity for precrystallized cocoa butter (shear crystallizer, outlet temperature = $25^{\circ} \mathrm{C}$, mass flow $=20 \mathrm{~kg} / \mathrm{h}$ ).

Figure 6B demonstrates the solidification time $t^{*}$ (the time where $\left.\eta\left(\dot{\gamma}=28.4 \mathrm{~s}^{-1}\right)=1 \mathrm{~Pa} \cdot \mathrm{s}\right)$ as a function of viscosity. The data could be approximated by a power law trendline. Up to a viscosity of $0.3 \mathrm{~Pa} \cdot \mathrm{s}$ a significant reduction of solidification time $t^{*}$ can be seen. At values above $0.3 \mathrm{~Pa} \cdot \mathrm{s}$, there is a further but more modest reduction of solidification time. According to the upper line in Figure 5 a viscosity value of 0.3 $\mathrm{Pa} \cdot \mathrm{s}$ corresponds to a crystal content of about $0.4 \%$ in precrystallized cocoa butter. This calculation is based on the assumption of $100 \% \beta_{\mathrm{V}}$-modification. Thus, solidification time was significantly reduced, with cocoa crystal content increasing to a limit of $0.4 \%$. Higher crystal masses apparently decrease solidification time $t^{*}$ at a much lower rate.

NIR calibration data show good correlations with measurements of viscosity (Fig. 7), crystal content $(R=0.975)$ and slope $(\mathrm{R}=0.945)$. This suggests that NIR spectra can be correlated with microstructural information related to the size, shape, and quantity of cocoa butter crystals. It is, however, difficult to investigate the cause for such correlations because they are derived statistically, not causally. Limiting the wavelength to more narrow windows and then comparing the quality of correlations deduced would be one way of further investigating the reason for such correlations. Such windows would be selected according to known regions for overtone vibrations of characteristic functional groups of cocoa butter molecules.

Constant chocolate outlet temperature. A good correlation of data for the $s$-value of precrystallized chocolate was found $(R=0.973)$. Thus, calibration of NIR spectroscopy based on a real chocolate system by means of temper curve analysis was possible.

Application of the NIR calibration model. NIR calibration models were developed based on cocoa butter experiments (as described above) and were applied in a new set of experiments at constant outlet temperature $\left(25.0^{\circ} \mathrm{C}\right)$. NIR calibration models therefore were used subsequently to determine in-line data for viscosity, melting enthalpy, and slope. Viscosity and melting enthalpy (Fig. 8), as measured by calibrated NIR, increased with higher rpm (as shown for cocoa butter at constant

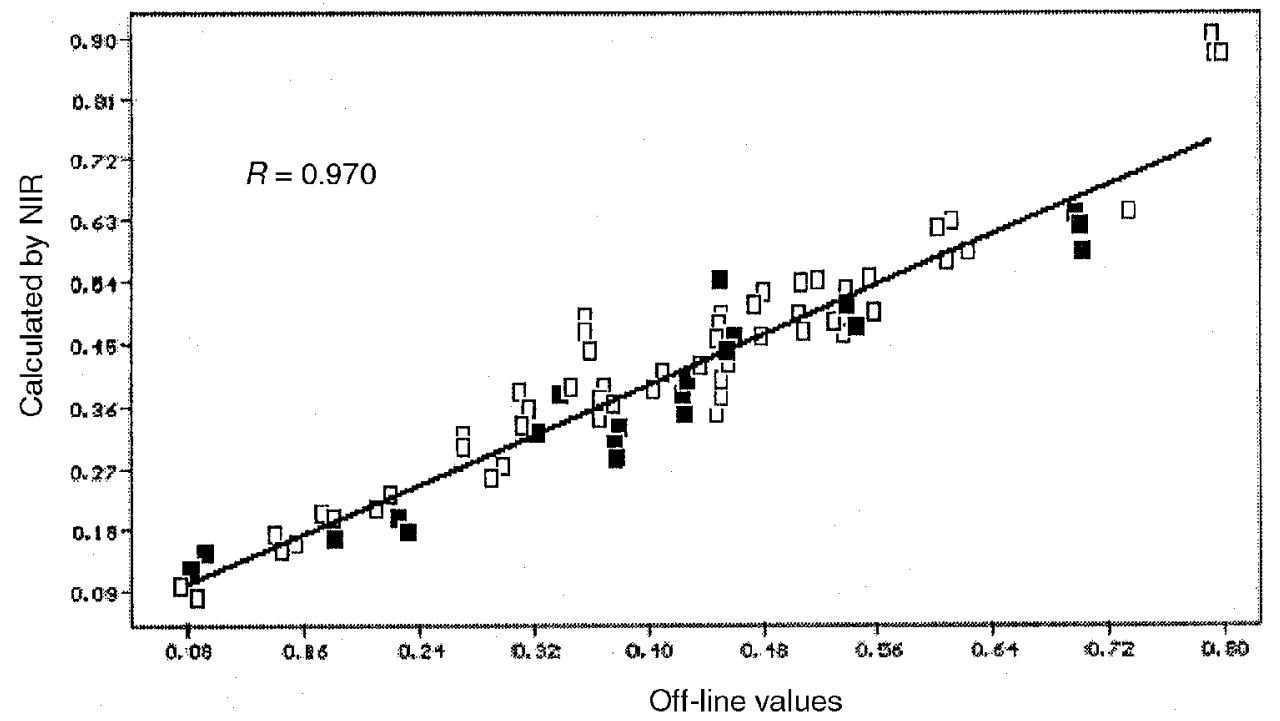

FIG. 7. Near-infrared (NIR) calibration model for quantitative measurement of viscosity for precrystallized cocoa butter ( $x$ axis: viscometer V88; $y$ axis: NIR calculation). Open symbols $(\square)$ represent data points on which correlation is based. Solid symbols (घ) represent data points on which correlation has been checked. 


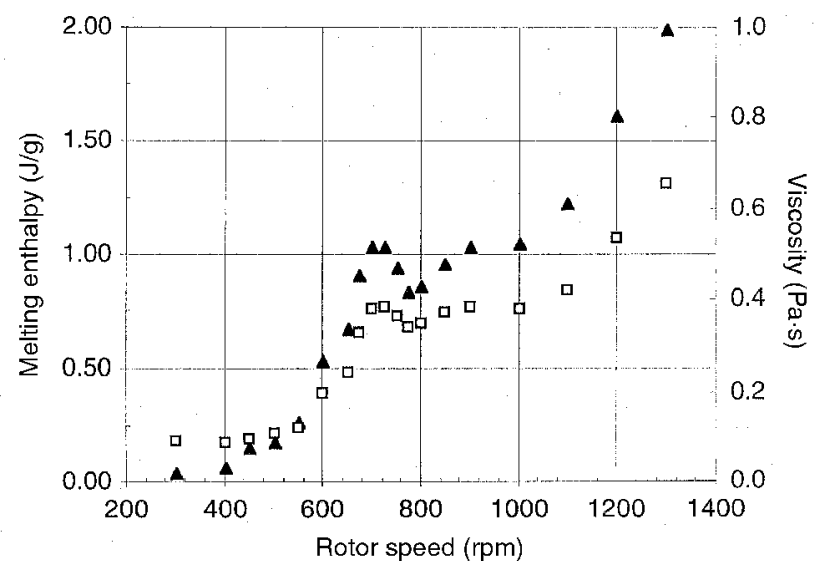

FIG. 8. Melting enthalpy and viscosity (both in-line near-infrared measurements) as a function of rpm for precrystallized cocoa butter (shear crystallizer, outlet temperature $=25^{\circ} \mathrm{C}$, mass flow $=20 \mathrm{~kg} / \mathrm{h}$ ).

outlet temperature). At $700 \mathrm{rpm}$ there was a peak. A peak at the same rpm could also be detected for slope (data not shown), but with a minimum instead of a maximum. Because of smaller rpm steps this effect appears more clearly in the online recorded data shown here. When realizing more accurate exit temperature settings $\left(25.07 \pm 0.01^{\circ} \mathrm{C}\right)$ within a tighter rpm range of 550-850 rpm, in a repetition of the set of experiments shown, a steadier increase of on-line viscosity (Fig. 9) and slope data could be found (data for slope not shown). This demonstrated the high sensitivity of measurement data to the exact regulation of exit temperature. Whether this is directly linked to a temperature change or indirectly to a change in the crystal structure cannot be further distinguished.

Another set of NIR application experiments was carried out at three different but constant cooling temperatures (22.6, 23.0, and $23.4^{\circ} \mathrm{C}$ ). Off-line viscosity (Fig. 10) for various mass flow rates (range: $17.5-25 \mathrm{~kg} / \mathrm{h}$ ) at constant cooling temperatures $\left(\approx 23^{\circ} \mathrm{C}\right)$ showed maxima in the range of $700-800 \mathrm{rpm}$. A plot of outlet temperatures (Fig. 11) against rpm showed minima between 500 and $1000 \mathrm{rpm}$. Standard deviations of outlet temperatures were $\pm 0.1^{\circ} \mathrm{C}$ for a set rpm.

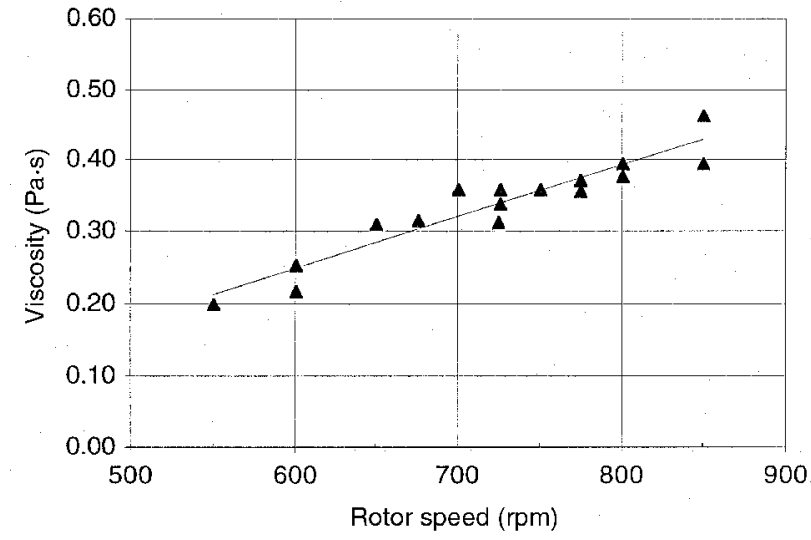

FIG. 9. Viscosity (on-line near infrared) as a function of rpm for precrystallized cocoa butter (shear crystallizer, accurate outlet temperature setting $25.07 \pm 0.01^{\circ} \mathrm{C}$, mass flow $=20 \mathrm{~kg} / \mathrm{h}$ ).

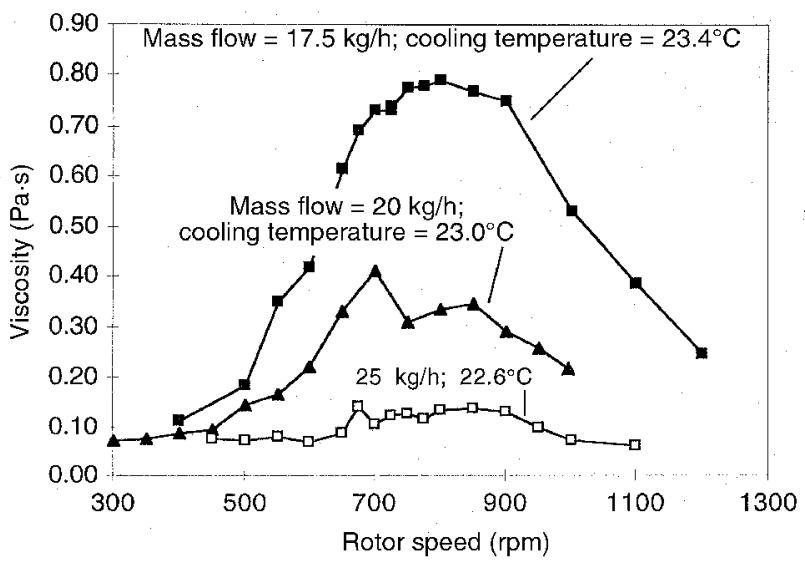

FIG. 10. Viscosity as a function of rotor speed and mass flow (constant cooling temperatures); the mass flow of $25 \mathrm{~kg} / \mathrm{h}$ was based on Bohlin V88 (Cranbury, NJ) viscometer, $\eta\left(\dot{\gamma}=28.4 \mathrm{~s}^{-1}, t=21.7 \mathrm{~s}\right)$; the viscosity values for the mass flows of 17.5 and $20 \mathrm{~kg} / \mathrm{h}$ are based on near-infrared measurements.

Below $700 \mathrm{rpm}$ the decrease in cocoa butter outlet temperature with increasing rpm is related to improved heat transfer/mixing. Above the $700 \mathrm{rpm}$ range energy dissipation leads to an increase in temperature. If residence time in the shear gap is increased by lower mass flow rates the optimal heat transfer is reached at lower rpm. Thus the minima in outlet temperature (Fig. 11) are the cause for the occurrence of maxima in the viscosity curves (Fig. 10).

\section{REFERENCES}

1. Windhab, E.J., E.A. Niediek, and L. Rolfes, TieftemperaturScherkristallisation-Neue Aspekte der Temperiertechnik, Süsswaren 3:32-37 (1993).

2. Ziegleder, G., Vorkristallisation von Schokoladen-Einflüsse Durch Produkt und Maschine, Süsswaren 1-2:54-58 (1993).

3. Windhab, E., Ueber die rheologischen Eigenschaften vorkristallisierter Schokoladenmassen, Proceedings of ZDSSchokotechnik-Internationale Konferenz, Solingen (1987).

4. Ziegleder, G., Fettreif nach optimaler Vorkristallisation? Proceedings of Schokotechnik, Koeln, Zentralfachschule der Deutschen Suesswarenwirtschaft (1994).

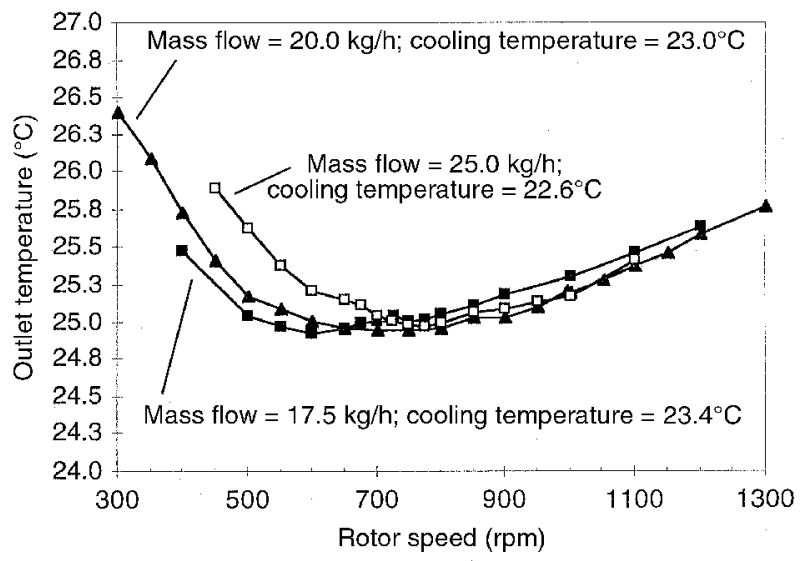

FIG. 11. Cocoa butter outlet temperature as a function of rotor speed at constant cooling temperatures $\left(22.6^{\circ} \mathrm{C}, 23.0^{\circ} \mathrm{C}\right.$ or $\left.23.4^{\circ} \mathrm{C}\right)$. 
5. Kleinert, J., Enthalpie-Kuren-Hilfsmittel zur Beurteilung der verarbeitungstechnischen Eigenschaften von Fetten und Fettmischungen, Rev. Int. Choc. 28:54-69 (1973).

6. Motz, R.J., Die Messung des Temperiergrades von Schokolade, Ibid. 12:470-476 (1957).

7. Ziegleder, G., K. Becker, M. Baumann, and O. Rosskopf, Die Kristallisation von Schokoladenmassen-Teil II: Vorkristallisation und Temperiergrad, Zucker Süsswaren Wirtsch. 7:238-243 (1988).

8. Breitschuh, B., and E.J. Windhab, Direct Measurement of Thermal Fat Crystal Properties for Milk-Fat Fractionation, J. Am. Oil Chem. Soc. 73:1603-1610 (1996).

9. Schuster-Salas, C., and G. Ziegleder, DSC-Messung des Temperiergrades fliessfähiger vorkristallisierter Schokolademassen unter Produktionsbedingungen, Zucker Süsswaren Wirtsch. 9:324-326 (1992).
10. Einstein, A., Eine neue Bestimmung der Molekulardimensionen, Ann. Physik 19:289-306 (1906).

11. Einstein, A., Berichtigung zu meiner Arbeit: "Eine neue Bestimmung der Moleküldimensionen," Ann. Physik 24:591-592 (1911).

12. Weipert, D., H.-D. Tscheuschner, and E. Windhab, Rheologie der Lebensmittel, Behrs Verlag, Hamburg, 1993, p. 439.

13. Bolliger, S., Gefrierstrukturierung in Lebensmittelsystemen Unter Mechanischem Energieeintrag [Freeze Structuring in Food Systems Under Mechanical Energy Input (Cocoa Butter, Ice Cream)], Ph.D. Thesis, Department of Food Science, Swiss Federal Institute of Technology (ETH), Zurich, Switzerland, ETH Ph.D. Thesis 11914, 1996.

[Received November 21, 1997; accepted February 27, 1999] 